\title{
Reviving Material Theories of Induction
}

\author{
John P. McCaskey
}

\section{Reviving material theories of induction}

John D. Norton says that philosophers have been led astray for thousands of years by their attempt to treat induction formally (Norton, 2003, 2005, 2010, 2014, 2019). He is correct that such an attempt has caused no end of trouble, but he is wrong about the history. There is a rich tradition of non-formal induction in the writings of, among others, Aristotle, Cicero, John Buridan, Lorenzo Valla, Rudolph Agricola, Peter Ramus, Francis Bacon, and William Whewell. In fact, material theories of induction prevailed all through antiquity and from the Renaissance to the mid-1800s. Recovering these past systems would not only fill lacunae in Norton's own theory but would highlight areas where Norton has not freed himself from the straightjacket of formal induction as much as he might think. The effort might also help us build a new theory of induction on the ground Norton has cleared for us. This essay begins that recovery and invites that rebuilding. ${ }^{1}$

\section{Formal vs. Material theories of induction}

The distinction between formal and material theories of induction was first drawn, at least under those names, in the 1840s. The inductive system of Francis Bacon had prevailed for two hundred years, and some philosophers were starting to complain about that, most influentially a professor at Oxford University named Richard Whately. ${ }^{2}$ Bacon's induction was an extension of Renaissance classification logic ("topics-logic”). It was orderly and methodical, but it was not

\footnotetext{
${ }^{1}$ The essay will not defend particular formal systems against Norton's attacks. The attacks appear to me, in the main, correct. The essay also does not consider the extent to which Norton's attacks would apply to formal systems he does not critique.

2 The view that Baconian induction was unproductive is a recent artifact of misunderstanding it and runs counter to what was said by practicing scientists from the 1620 s to the 1840 s. For corrections to the misunderstanding, see Rees (2004) and Snyder (2006).
}

Final preprint as accepted for publication in Studies in History and Philosophy of Science Part A, date TBD.

Please cite the published version at https://doi.org/10.1016/j.shpsa.2019.12.006.

@2020 John P. McCaskey, mailbox@johnmccaskey.com, licensed under CC BY-NC-ND 4.0. 
formal. It had no schema or template as a syllogism or algebraic equation does. In 1826, (Whately, 1826) proposed that it would be better to treat induction as a kind of syllogism-in particular an enthymeme with the major premise suppressed. Until then, the only attempt to make induction formal had been the Scholastic method of complete enumeration-turning induction into an enthymeme with the minor premise suppressed, not the major. In the Scholastic approach, the schema was " $\mathrm{P}_{1}$ is $\mathrm{Q}, \mathrm{P}_{2}$ is $\mathrm{Q}, \mathrm{P}_{3}$ is $\mathrm{Q}$, etc.; $\mathrm{P}_{1}, \mathrm{P}_{2}, \mathrm{P}_{3}$, etc. are $\mathrm{Q}$; therefore all Ps are Q." This has problems, the biggest of which is that it works only when the enumeration could be complete. Whately proposed an alternate schema: " $\mathrm{Q}$ is true of $\mathrm{P}_{1}, \mathrm{Q}$ is true of $\mathrm{P}_{2}, \mathrm{Q}$ is true of $\mathrm{P}_{3}$, etc.; what is true of the observed is true of all; therefore $\mathrm{Q}$ is true of all Ps.”3 John Stuart Mill embraced Whately's proposal and gave us the formulation common today, that behind every induction lies an unstated major premise that affirms the uniformity of nature (Mill 1843, book 3, chapter 3, section 1; Ducheyne and McCaskey, 2014).

A philosophical battle ensued. Defending Baconian induction, labeled "material" induction by its opponents, was William Whewell. Defending formal inductions, in either the old Scholastic model or the new Whatelian one, were the historian of logic William Hamilton, philosopher John Stuart Mill, and Mill's many followers. The Whatelian schema prevailed, and attention turned to how one would know if a uniformity of nature was operative in the case at hand. Mill suggested that probability, a science already two hundred years in the making, could be used, but he did not see how (Mill 1843, book 3, chapter 18, section 6). W. Stanley Jevons answered the call, and for the first time someone connected induction to probability (Jevons 1874, 262-263, 279-281, 307-312). Modern confirmation theory began. In fifty years, the mid-1820s to the mid-1870s, Whately's intended revolution had been completed. (Only after that was Hume's earlier skepticism about causality considered relevant to induction. ${ }^{4}$ ) All

\footnotetext{
${ }^{3}$ Whately first marked his proposal with the simple footnote, "* Not the minor, as Aldrich represents it." Over the years, as the proposal attracted attention and criticism, the note was incorporated into the text and greatly expanded.

${ }^{4}$ In the 1870s, Hume was known as an historian of England and the author of an important essay against miracles. His epistemological treatises were out of print and attracted little interest. If Hume was thought to have any relevance to induction, it was as a defender of Mill's uniformity of nature. Thomas H. Green, founder of
} 
the formal schemas that John Norton attacks derive from the victory of Whately's formal approach over the Baconian/Whewellian/material approach. Formal treatments have become so dominant that it is nowadays a common error to think induction has always been treated as a formal inference. Norton says the formal approach has prevailed for millennia. It has not. It just feels that way.

Norton surveys what he considers the main attempts to give induction a formal inferential structure, such as enumerative induction, analogy, experimental reproducibility, inference to the best explanation, and Bayesian probability, each an "inductive logic." ${ }^{5} \mathrm{He}$ concludes that none apply in all cases, that is, none apply "universally." When one works, it is because something specific to the problem at hand justifies its use. Consequently, the inductive logic itself does not do much work. It is the local facts that warrant, or "power" (to use Norton's term), the inference.

Marie Curie, for example, made a claim about the crystalline structure of all radium chloride based on a tiny sample. Norton says this might look like a successful use of enumerative induction, an inference on the model (as Norton understands such induction) “Some (few) A’s are B. Therefore, all A's are B” (Norton 2019, 9, chapter 1, subchapter 5). But, he rightly says, it was not the formal model that justified the inference. Nothing in that schema could tell Curie why she could extrapolate crystalline structure but not other properties. It was, Norton says, her background knowledge of chemistry, in this case, Haüy's principle about crystals, that justified the inference. She was, Norton explains, not applying any special inductive method. She was just going about the "normal business of research chemists" (Norton 2019, p. 25, chapter 1, subchapter 9).

British Idealism, raised interest in Hume's attempted defense and insisted that it failed. Green's readers and students went further and concluded that Hume's failure amounted to an unanswerable undermining of the very possibility of induction. See Green's two-part introduction to Hume (1874), reprinted in Green (1885, 1-371).

${ }^{5}$ Norton does not consider John Stuart Mill's Methods of Experimental Inquiry, E. F. Apelt's proposal that induction is a disjunctive syllogism, or the ampliative logics of Diderik Batens. Such considerations would not, I think, alter my arguments in the current essay.

Preprint accepted for publication in Studies in History and Philosophy of Science, date TBD.

Please cite the published version at https://doi.org/10.1016/j.shpsa.2019.12.006

(C)2020 John P. McCaskey, licensed under CC BY-NC-ND 4.0 
Reproducibility of experiments is held out as a gold standard of inductive science. But Norton surveys cases where we accept an hypothesis even when experimental results provide evidence against it (such as Miller's test of relativity) and cases where we reject an hypothesis even when experimental results confirm it (such as intercessory prayer). There is nothing in the experimental schema that would distinguish the cases. We rely on the factual context. The facts, not the schema, Norton says, power the inductive inference.

Norton considers several more inductive schemas and concludes that even when we use some schema, it is not the schema that does the work; it is the facts at hand. It is not the form but the matter that warrants the inferences we draw. There is no single context-less schematic form of inductive inference that is always usable, in the way there is for algebraic inference or deductive inference. "All inductions are local" and "There are no universal rules of inductive inference" are Norton's slogans for his material theory of induction.

The latter claim is ambiguous and can be misleading. It could mean that common regulators of good reasoning-the laws of identity and contradiction, dictum de omni et nullo, rules against equivocation, rules governing reciprocity and transitivity, and so on-simply do not apply once we enter the realm of induction. By this, induction would be a topsy-turvy world in which something could be both itself and its opposite, what is true of all instances might not be true of any, and, even though A implies B and B implies C, A would not imply C. I presume Norton does not mean this. He seems to accept that there are universal (though unspecified) rules of good reasoning that apply in induction just as they do in, say, deduction or mathematics.

Norton uses "universal" instead to indicate that there is no one set of rules that are effective and sufficient in all cases of inductive reasoning, that in some cases an investigator can use enumerative induction, in others conventional probability, in others Bayesian statistics, in others analogy, in others inference to the best explanation, etc.- - that no one inferential system 
of induction works at all times in all cases in all domains of inquiry and there are no rules indicating which one will work in a particular case.

That we use different systems of induction in different situations is not itself remarkable. We can say the same about deduction and mathematics. Sometimes we need to use a firstfigure syllogism, sometimes a second-figure; sometimes we use geometry, sometimes set theory. But, by Norton's understanding, formal inductive methods differ from deductive or mathematical methods in that, while the latter will not produce conflicting results, formal inductive ones might. If a math problem can be solved using either geometry or number theory, the result will be the same either way. But (understood formally) analogical reasoning, Bayesian analysis, and enumerative induction might produce conflicting results. An analogical argument that the eye was crafted by an intelligent designer might conflict with an argument that uses inference to the best explanation. In Norton's system, not only is there no one universal inductive logic that works everywhere, there is no universal rule that says which local rule should be given preference. This too will need to be determined by the facts at hand.

So the only universal rule specific to Nortonian induction theory is that there are no universal rules specific to induction. This should start to worry us, and not only because of the hint of self-refutation. Norton is saying that if we gather together all the cases of what we would now call successful inductive scientific research, we find they have nothing distinctive in common. Some rely on analogy, others on statistics, others on experimentation, etc., and even those of one type are too incommensurable with those of the other types for us to know $a$ priori which method we should apply and which we should not. We must simply let the facts of the matter in each case warrant the inferences we draw in that case. But what, then, holds them all together as cases of induction? Why do we class them as such in the first place? Indeed, should we?

\footnotetext{
Preprint accepted for publication in Studies in History and Philosophy of Science, date TBD. Please cite the published version at https://doi.org/10.1016/i.shpsa.2019.12.006 (C)2020 John P. McCaskey, licensed under CC BY-NC-ND 4.0
} 


\section{Ampliation and induction}

Crucial to understanding Norton's theory is his definition of induction. It is fairly conventional for induction theory nowadays but differs profoundly from theories that prevailed earlier. And though his definition is common, he works out an overlooked implication. He exposes a very real problem in the definition itself.

The common understanding today is that induction is a kind of propositional inferencethe drawing of a propositional conclusion based on propositional premises. In particular, it is any inference that is "ampliative," a term introduced by William Hamilton. To understand the importance of the term, it is worth understanding its history.

In the 1871 Critique of Pure Reason, Immanuel Kant distinguished judgments that are analytisch from those that are synthetisch. The first, he said, are erläuternd, the second erweiterend. Analytisch judgments are true by the very meaning of the terms. The predicate explicates (erläutern), or makes explicit, a fact contained in the concept of the subject.

Synthetisch judgments are otherwise. The predicate expresses some new fact not contained by necessity in the concept of the subject. It amplifies (erweitern); it goes beyond what was given. In 1846, Hamilton said the English pair "analytic" and "synthetic" were misleading and that it would be better to use "explicative" and "ampliative."6 By the early 1860s, Hamilton's proposal was widely known, and the equating of "analytic" with "explicative" and "synthetic" with "ampliative" was common.

The distinction applied only to judgments and propositions, not to reasoning or inferenceat least until C. S. Peirce proposed otherwise. In 1878, he wrote, "All our reasonings are of two kinds: 1. Explicative, analytic, or deductive; 2. Amplifiative, synthetic, or (loosely speaking) inductive. In explicative reasoning, certain facts are first laid down in the premises" (Peirce 1878, p. 711, italics in original). A new statement, one whose truth is contained in the premises

\footnotetext{
6 "No subject, perhaps, in modern speculation, has excited an intenser interest or more vehement controversy, than Kant's famous distinction of Analytic and Synthetic judgments a priori, or, as I think they might with far less of ambiguity be denominated, Explicative and Ampliative judgments." William Hamilton, in a footnote to Reid (1846, p. 787).
}

Preprint accepted for publication in Studies in History and Philosophy of Science, date TBD. Please cite the published version at https://doi.org/10.1016/j.shpsa.2019.12.006 (C)2020 John P. McCaskey, licensed under CC BY-NC-ND 4.0 
and that has merely "escaped attention," is then made explicit (Peirce 1878, 711). "But synthetic reasoning is of another kind. In this case the facts summed up in the conclusion are not among those stated in the premises. They are different facts, as when one sees that the tide rises $m$ times and concludes that it will rise the next time. These are the only inferences which increase our real knowledge" (Peirce 1878, 711). Peirce goes on to use "ampliative," "amplifiative," and "synthetic" interchangeably. Later, "ampliative” dropped out of favor for translating Kant's synthetisch and for characterizing judgments, but its application to inference and its association with induction became canonical. ${ }^{7}$

Now it used to be that induction (inductio in Latin, epagōgē in Greek) was defined as a progression from knowledge of particulars to universal knowledge. Induction was inherently open-ended. The result subsumed more than went into its formation. It was not presumed that this progression was inherently unreliable. Philosophers did not call induction ampliative, but once the word was coined, it became natural and logical enough to do so.

But transfer of the term from judgments to inferences created (or exposed or amplified) a problem. "Goats are omnivores" is a synthetic statement. So too is "Goats are immortal." The second might be false, but we can still treat it as a proposition. What about "Roses are red; Socrates is a man; therefore, goats are immortal"? Should we treat this as an inference at all, even an incorrect one? Should we treat it as an induction? If an ampliative inference is one whose conclusion is not already contained in the premises, this appears to qualify. But we are uncomfortable allowing just any string of sentences followed by a "therefore" to count as an inference. We do not want to say that induction is just any conclusion whose truth is not contained in the premises. This would glorify countless wanton and arbitrary claims.

We want to say that in an inductive inference, there needs to be some reason to believe the conclusion is true. To block wanton inferences, Norton adds a qualifier: An inductive inference

\footnotetext{
${ }^{7}$ A reference work in 1881, the glossary of philosophical terms in Monck (1881) still shows the earlier conception. Peirce's view spread by way of entries he wrote in Whitney (1889), such as for "inference," "induction," and "logic."
} 
is any "licit" inference that leads to a conclusion not necessitated by the premises (Norton 2019, p. 1, chapter 1, subchapter 0). It needs to follow some law. It must meet some standard of goodness. We must have some good reason to believe it is true.

Norton also accepts the presumption-again standard since Peirce expanded "ampliative" to include inferences-that for a conclusion to be "contained in" the premises means that it can be inferred deductively from the premises. The presumption is that only deductive inferences are necessary. For a conclusion to be inductive, there must be the possibility that the inference is not certain. There must be "inductive risk." If there is none, the thinking goes, the inference is deduction.

This creates a strange situation. Imagine a team of scientists trying to discover the properties of a newly crafted material. They look for analogies, run experiments, test hypotheses, seek explanations, and calculate statistical correlations. They discover the material's melting point, its boiling point, and how it interacts with other materials. But some of their conclusions are only true for the most part. They continue their research, looking for causes of the exceptions, working exactly as they had before. Now, are the scientists using an inductive method or a deductive one? By the modern understanding, conclusions true only most of the time (assuming true premises) are-and were-discovered using induction, the others are-and were-discovered using deduction. Yet the scientists would say they used the same methods for both. After one year of work, the scientists know, say, that a chemical process fails occasionally. On the 366th day of proceeding exactly as they had for a year, they discover that a particular isotope causes the exception. Should they say, "We thought we had been using inductive methods, but now that we have succeeded, we find our methods had been deductive all along"? That would be weird.

Norton provides a real-world example, namely, Marie Curie's claim that radium chloride forms the same type of crystal as barium chloride does. She had access to miniscule amounts of radium chloride yet claimed that all specimens of it would form the same sort of crystals that

Preprint accepted for publication in Studies in History and Philosophy of Science, date TBD.

Please cite the published version at https://doi.org/10.1016/j.shpsa.2019.12.006

(C)2020 John P. McCaskey, licensed under CC BY-NC-ND 4.0 
barium chloride does. (Even if Norton's historical account of what happened or what Curie was thinking is inaccurate, the account tells us what Norton thinks about deduction and induction..$\left.^{8}\right)$ Her extrapolation, Norton explains, was a straightforward application of Haüy's principle that all specimens of a chemical form the same sort of crystal. Norton explains that if the principle really were universal and there were no exceptions, then Curie's inference would have been a deduction; yet because there are exceptions (some chemicals can in fact form more than one type of crystal), Curie's inference was an induction. Haüy's principle was generally but not universally true, and that fact, Norton says, makes any inference using the principle an induction rather than a deduction (Norton 2019, 19, chapter 1, subchapter 8). By this thinking, had Curie made ten inferences based on ten chemical laws, without first checking which allowed exceptions and which did not, she would not have known when she was using deduction and when induction.

Now maybe we can craft up a tidy response to this oddity. But we should be uncomfortable. And Norton's forceful conclusions should make us even more so. He has shown that inductive logics have nothing in common except that they produce uncertain inference. But even the exception is not really a discovery. We can be sure they have that one thing in common simply because we define induction that way. If you or I or Aristotle or Bacon or a modern Bayesian has a way to fully secure what had been an insecure inference, that inference becomes ipso facto a deduction. If we remove all the inductive risk, the inference is no longer inductive. By this way of thinking, we should not be troubled by some "Humean"

\footnotetext{
8 I think Norton overemphasizes the centrality of Haüy's principle. Curie had much more background knowledge than that. It is true she did not have access to much radium chloride, but her whole process of extracting it was based on repeated fractional crystallizations. Nearly everything she knew about radium chloride was based on working with it and barium chloride, including in crystal form, side-by-side. Crystallography was her husband's specialty. She and her husband published their discovery of radium in December, 1898. By 1902, someone in Paris could buy a gram of radium for ten dollars. The remarks about isomorphism of barium and radium chlorides that Norton cites appeared in 1904, in a periodical that included advertisements of radium for sale. By that time, Curie also had the benefit of Friedrich Rinne's detailed comparison of barium and radium bromide, Rinne (1903). Curie's extrapolation was a broad integration of extensive chemical knowledge, performed over several years, not a simple application of Haüy's principle.
} 
argument that inductive inferences are insecure. Induction is insecure merely because we define it to be. ${ }^{9}$

Norton has examined the main current theories of induction that proponents claim can be formalized. He concludes that they have nothing in common except that they produce conclusions that we have reason to think are true but that we know might not be. But the situation is even worse than Norton lets on, for he has not examined large classes of everyday inferences that also fit his definition of induction. Based on several background facts, I infer that my stepson will arrive home from school today between 4:00pm and 4:30pm. I infer that there will be an election for president of the United States in the year 2032. A friend has been diagnosed with pancreatic cancer; I infer he will die soon. Knowing all that I do, I infer that the diner across the street opened today at noon. I cannot get through an hour of life without making inferences that I have good reasons to believe are valid but that I know might not be, inferences that Norton must class as inductive.

Little good and much bad comes from trying to have one concept for all uncertain inferences. There are just too many unrelated reasons for an inference to be uncertain. There is simply nothing useful and distinctively true about all cases. We do not need a concept for inferences that are uncertain any more than we need a concept for colors that are not green or vacations that are unhappy. Creating such would undermine and not aid clear thinking. Norton's attack on a few kinds of uncertain inference should help us see that we are making a categorization mistake with the current conception of induction.

We may not even need a concept for all certain inferences. "All men are mortal; Socrates is a man; therefore, Socrates is mortal." "The perimeter of the square is 8 inches; therefore, the area is 4 square inches." "A is to the right of B; therefore, B is to the left of A." Should we call all of these deductions? Would it not be more useful to say deductive, mathematical, and immediate are three kinds of certain inference?

\footnotetext{
${ }^{9}$ See note 4 for why the common argument that induction is insecure should not in fact be attributed to David Hume.

Preprint accepted for publication in Studies in History and Philosophy of Science, date TBD.

Please cite the published version at https://doi.org/10.1016/j.shpsa.2019.12.006

(C)2020 John P. McCaskey, licensed under CC BY-NC-ND 4.0
} 
Even if we do need a single term for uncertain inference, that term should not be "induction." Philosophers have spent two thousand years investigating how to base universal and certain scientific laws on limited experience. We lose our ability to understand those two thousand years of research if we decide in advance that there can be no such laws and that we might as well just re-use the term for any uncertain conclusion inferred from true premises, from "All mammals give birth to live young" to "Chris and Morgan will get married next month.” If we try, eventually an astute philosopher such as John Norton will notice that no schematic form of reasoning can account for all such inferences. There is simply nothing distinctive and useful that we can say about all of them. There is nothing to learn about them by treating them as of one kind.

\section{Turning Back the Calendar on Induction}

Norton insists that induction should not be treated formally. He mistakenly thinks it always has been. In fact, it has been only since the nineteenth century. What if we accept Norton's attack on formal treatments but reject his view that we need to start from scratch? Let us look at some differences between his proposal and older ones in an attempt to turn back the calendar and recover ideas about induction that prevailed when induction was treated nonformally.

Norton is presumably just unaware of the rich history of material induction. Few philosophers researching induction nowadays would think to study Socrates, Cicero, Galen, Lorenzo Valla, Rudolph Agricola, or Peter Ramus. And the theories of more familiar material inductivists such as Francis Bacon, John Herschel, and William Whewell seem unworthy of much study, since when we go looking for induction, we go looking for formal systems of inference and these authors offer none. ${ }^{10}$ Even the explicit debate in the $1840 \mathrm{~s}$ and '50s between material and formal has gone largely unnoticed.

\footnotetext{
${ }^{10}$ Aristotle belongs on the list of material inductivists but the misunderstanding is different. We go looking for a formal system and do find one, or seem to, in Prior Analytics B 23. But, since late antiquity, the text of the chapter has been misread. See McCaskey (2007). 
But Norton might also claim his material theory is the first simply by how he classifies. His criteria for calling a theory formal are broad. If an inductivist proposes any criteria, method, process, standard, rule, or norm, it seems, Norton calls the proposal formal. In the past the theorist most cited as a material inductivist was Francis Bacon. He railed against the schematic formality of Scholastic induction. He insisted that the whole formal apparatus collapses if concepts are not rigorously defined, and that that is not possible until one identifies the essential cause that makes something an instance of a class. He outlined an iterative process by which we methodically identify similarities and differences and use the result to carefully define terms, and then showed how universal propositions follow directly from those definitions. Norton calls this method formal. But only with strained reformulation and an excision of the system's heart could one give Bacon's system a formal inferential schema, where the conclusion follows only from the structure of the argument and not from the facts at hand. This is so even if Bacon thinks induction can be performed methodically. It would be similarly missing the point to try casting the inductive methods of Socrates, Cicero, Valla, Ramus, or Whewell as formal schemas. Yet all these authors treat induction normatively and insist there are universal standards for distinguishing good inductions from bad ones.

Indeed, it would be as difficult to treat their systems as formal schemas as it would be to treat methods of abstraction or of concept-formation as formal schemas, and for the same reasons. How does, for example, a child form the concepts of home, loyalty, and fragile, and how do those concepts evolve as the child matures? I cannot think what benefit there would be to treating the process as a formal schema. Yet surely concept-formation is a normative process. There are standards that distinguish doing it well from doing it poorly. People can form illogical concepts. Similarly, that a theory of induction proposes specific criteria by which to evaluate an induction does not make that theory a formal one. There can be normative principles without formality. I think it best to follow the older classification and treat the inductive theories of Socrates, Valla, Bacon, and Whewell as material, not formal.

\footnotetext{
Preprint accepted for publication in Studies in History and Philosophy of Science, date TBD.

Please cite the published version at https://doi.org/10.1016/i.shpsa.2019.12.006

()2020 John P. McCaskey, licensed under CC BY-NC-ND 4.0
} 
Norton's argument for his theory is, naturally enough, one that fits his model of a material induction. He says many formal theories have been tried and all have failed, and that any inductions we consider successful can be explained by a material theory (Norton 2019, p. 1, chapter 2 , subchapter 1 ). So even though the material theory might not be true-someday someone might find a formal theory that works or an inductive inference inexplicable by a material theory-we have good reasons to believe the material theory is true. Those good reasons are, as always in Nortonian induction, just the facts of the matter in the particular branch of inquiry, here, in the philosophy of scientific inference. In this example of his induction at work, we have, Norton says, "a solid case for the material theory" (Norton 2019, p. 1, chapter 2, subchapter 1). It might not be true, but we have good reasons to believe it is.

Prior non-formal theories were defended differently-but again, the defenses were instances of those theories in practice. Bacon attacked the Scholastics' formal inferencesinductive and deductive-by saying they were made from propositions and the propositions from concepts, and so if concepts were ill-defined, the inferences would be unreliable. Inversely, he showed how, using good classification logic, well-defined concepts could lead directly to reliable, exceptionless, necessarily true, universal statements. His arguments do not follow a formal deductive schema. But they do follow non-formal rules for reasoning-rules about parts and wholes, about essential natures, about opposition, and about conceptual dependency. And he is clearly on to something. You cannot, for example, say anything reliably true about swans if you do not have reliable criteria for deciding what is and is not a swan. Bacon's claim is not an inference that is true because it fits a schematic inferential pattern. It is an inference that is true by the nature of propositions and the relationship of propositions to concepts. In Nortonian language, it is an inference warranted by local facts, facts specific to the domain of inquiry. But, contra Norton, it is an inference also warranted by non-formal rules of reasoning, that is, by rules for combining local facts in ways that justify inferences.

\footnotetext{
Preprint accepted for publication in Studies in History and Philosophy of Science, date TBD. Please cite the published version at https://doi.org/10.1016/i.shpsa.2019.12.006 @2020 John P. McCaskey, licensed under CC BY-NC-ND 4.0
} 
A large difference between Norton's and earlier material theories is simply their charters. Earlier theories attacked formal theories for failing to derive universal and certain knowledge from knowledge of particulars and then proposed some alternative way to do so. Norton's theory attacks each formal theory for claiming to be the best and only, accepts that each can be useful in particular situations, and then offers no universal advice on when to use which or what to do when different formal theories offer conflicting conclusions. Earlier material theories limited their remit to the secure derivation of universals from particulars and considered the inability to provide such a disqualifier. Norton's material theory embraces any inference whose conclusion we have reason to believe is true-but that we know might not be-and removes from consideration only those whose conclusion must be true. Nortonian induction is defined so broadly that we are forced to treat each case as a special case. A major step toward reviving a material conception of induction would be to return the very concept of induction to narrower limits, so that we can say something helpful that would apply to all instances. Inability to draw a certain conclusion should not be the defining characteristic.

\section{Locus of Ampliation}

Another major difference between Norton's system of material induction and earlier theories is that Norton embraces an aspect of his opponents' ideas that earlier material theorists considered the essential flaw in formal theories, namely a presupposition about the locus of ampliation. Aristotle said that epagōgē is a progression from particulars to a universal, but there is an ambiguity here. Did he mean universal and particular propositions? Or did he mean particular things and universal kinds? Did he mean we make multiple particular statements and draw from them one universal statement? Or did he mean we observe multiple particulars and group them to form one universal concept? Is induction a logic of propositional inference, or is it a logic of classification? In human cognition, does ampliation take place at the propositional level or the conceptual level? Herein lies the most important difference between material and formal theories of induction.

\footnotetext{
Preprint accepted for publication in Studies in History and Philosophy of Science, date TBD. Please cite the published version at https://doi.org/10.1016/i.shpsa.2019.12.006 (C)2020 John P. McCaskey, licensed under CC BY-NC-ND 4.0
} 
Formal theories presumed ampliation takes place at the propositional level. Material theories attacked formal theories for this, saying the open-endedness of universal statements is provided by our conceptual faculty not by our ability to draw inferences. As Bacon said, "a syllogism consists of propositions, and propositions consist of words, and words are the tokens and signs of notions. And therefore if the very notions of the mind . . are badly or carelessly abstracted from things ... everything falls to pieces" (Bacon 2000, "Plan of the Work," Silverthorne's translation, slightly modified.) As we might say now, unless we have an objective way to class some black thing as a swan, we can never know whether that thing refutes the hypothesis that all swans are white. On the other hand, if we have good objective criteria for, say, classifying metals, we can be positively certain that all magnets attract iron; in other words, inductive inferences can be certain and exceptionless.

Norton insists it is not any formal rules of reasoning that warrant inductive inference; it is just the facts specific to the domain under investigation. Inferences are "powered" by the facts, he says (Norton 2019, chapter 2). But this is just not saying much. Inferences require combining facts. A philosopher of scientific method is tasked with telling the scientist how facts should be combined. It is not enough to defer to the "normal business" of science and "routine problem[s]" handled the regular way (Norton 2019, p. 25, chapter 1, subchapter 9). The whole question is what should be normal and regular. Past material theories had extensive advice on how to perform inductions and that advice rested on the presumption that good inductions were powered by good classifications. Early in The Material Theory of Induction, Norton quotes at length a passage from Whewell, a material inductivist if ever there was one. Norton summarizes the passage: "Finding the right system of classification is what makes generalization possible” (Norton 2019, p. 17, chapter 1, subchapter 7). ${ }^{11}$ This was the very essence of material induction from Socrates and Aristotle to Bacon and Whewell. When one of

\footnotetext{
${ }^{11}$ Later, when discussing an example of analogy that Galileo drew, Norton (2019, 17, chapter 4, subchapter 8) says, "The inference is not driven as much by analogy as by subsumption of the moon into a larger class of illuminated bodies."
}

Preprint accepted for publication in Studies in History and Philosophy of Science, date TBD.

Please cite the published version at https://doi.org/10.1016/j.shpsa.2019.12.006

(C)2020 John P. McCaskey, licensed under CC BY-NC-ND 4.0 
them said it, they proceeded to offer extensive advice on how to obtain "the right system of classification.” Norton drops the subject.

But Norton is correct that finding the right system of classification is what makes any generalization possible. Had a Scholastic in the Renaissance posed the scientific query "French gunpowder gets hot when ignited; Russian gunpowder gets hot when ignited; Chinese gunpowder gets hot when ignited; does all gunpowder get hot when ignited?” Bacon would have mocked an attempt to survey more instances. Instead he would have said, as he did in book 2 of the Novum Organum, that we need to know what heat is (and what gunpowder and ignition are, topics he did not address in the Novum Organum). Bacon recommended an orderly approach that included making tables, performing experiments, drawing careful comparisons, distinguishing one-to-one and one-to-many relationships, and iteratively revising results until the researcher is willing to make the commitment that if the property is lacking, the instances will not be treated as a member of the class. Exceptionless universal statements are then possible. Ampliation occurs at the conceptual rather than the propositional level, and classification powers generalizations.

Bacon's system of induction described how to identify the characteristics that make something the kind of thing it is. He described how to identify one-to-one relationships and to distinguish cause from effect. The practical part of his system ran to a hundred and forty pages. Aristotle's system embraced not just one-to-one relationships but one-to-many relationships. The Posterior Analytics and the central books of the Topics lay out the system. He applies it in his many books on biology. William Whewell's system addresses how the ampliation that occurs at the conceptual level powers inferences at the propositional level. His Philosophy of the Inductive Sciences spanned three volumes. All of these systems are systems of induction, of progressing from knowledge of particulars to knowledge of universal scientific laws. All are material systems. None propose formal schemas for drawing conclusions true merely by the structure of the inference. All draw on a long, but now inadequately appreciated, tradition of

\footnotetext{
Preprint accepted for publication in Studies in History and Philosophy of Science, date TBD.

Please cite the published version at https://doi.org/10.1016/i.shpsa.2019.12.006

()2020 John P. McCaskey, licensed under CC BY-NC-ND 4.0
} 
logical but non-formal reasoning that begins with Socrates' search for what is true of all instances. Unfortunately, interest in this sort of logic waned after Richard Whately turned us toward the formal.

Though the difference between formal and material might seem from the examples to be plain enough, the distinction can be difficult to draw sharply. "Formal" could mean depending on a schematic structure, applicable without regard to the facts at hand, in the way that $7 \mathrm{x}+8 \mathrm{x}$ $=15 \mathrm{x}$ regardless of the value of $\mathrm{x}$, or "All $\mathrm{B}$ is $\mathrm{C}$; all $\mathrm{A}$ is $\mathrm{B}$; therefore all $\mathrm{A}$ is $\mathrm{C}$ " is true regardless of the referents for A, B, and C. "Material" would mean the opposite. But all formal inferences depend on the facts of the matter at hand. "Formal" and "material" are not opposites in the way "right" and "left" are. Rather "formal" and "material" have some sort of mutual dependence on one another. Norton observes that advocates of Bayesian induction admit that their formal procedures do not always work; nothing contained in the formal mechanics themselves indicate whether the mechanics do or do not apply in a particular case. It is not the form of Bayesian equations, Norton says, that power the induction; it is the facts of the matter at hand. But that is the same with something as unambiguously formal as algebra. It is not true that $7 \mathrm{x}+8 \mathrm{x}=15 \mathrm{x}$ for any value of $\mathrm{x}$. The equation fails if $\mathrm{x}$ is water, blue, or sing. But that does not make algebra any less formal or, when the matter justifies its use, any less valid, and there is little to gain by insisting that the matter and not the form "powered" the equation. Moreover, considered from the opposite direction, it is not true that every inference is sui generis, that it is only the facts of the matter and not any formal principles that justify an inductive inference. And finally, if the distinction were plain, Norton and I (with nineteenthcentury commentators) would not disagree so much on which inductive inferences to class as formal and which to class as material.

In the end, the whole distinction between formal and material systems of inference may not be very fruitful-or if it is, fruitful mostly because it directs us to a distinction more important and more fundamental. We want to draw reliable generalizations. How (if at all) we

\footnotetext{
Preprint accepted for publication in Studies in History and Philosophy of Science, date TBD. Please cite the published version at https://doi.org/10.1016/i.shpsa.2019.12.006 (C)2020 John P. McCaskey, licensed under CC BY-NC-ND 4.0
} 
can do so comes down to this question about how our minds work: In human cognition, where does ampliation occur, at the conceptual level or the propositional?

If we believe it occurs at the propositional level-if, that is, we think generalization enters human thought once we make particular statements and draw from them a general statementthen we will go looking for some schematic structure or structures, something formal, that all such propositional inferences must follow. Norton evaluated the major proposals and found that none work all the time and that there is no a priori rule for which works when. He says we might as well stop looking for one schematic form.

I agree but for a different reason. I propose that we will never find such a schema for inductive inference, simply because generalization does not enter human thought at the propositional level, not at the level of sentences, judgments, and inferences. It enters at the conceptual level, at the level of words and their meanings. Once we begin making propositional statements about swans or radium chloride or whether all magnets attract iron, we have already started to generalize. Just to form the concept of magnet is to subsume many instances under one thought. Once we start making judgments we can-and do-alter the cognitive integrations that are the thought. We are forced, for example, to decide what should be classed a magnet, a swan, or a sample of radium chloride. We iteratively build up the conceptual framework by which we can make statements generally, even universally, true.

We can and must guide the formation of that framework with norms about identity, noncontradiction, hierarchical consistency, parsimony, and other properties that Socrates struggled with when looking for the essence of piety. We need standards and principles. But these just do not lend themselves to schematic forms. They lend themselves instead to the kinds of rules that Aristotle extracted from what he saw Socrates do, which are not very different from the rules for induction that Francis Bacon laid down in book 2 of the Novum Organum, which are not very different from the rules of classificatory logic that practicing scientists use, and have always used, so successfully. The process is too iterative-and too

\footnotetext{
Preprint accepted for publication in Studies in History and Philosophy of Science, date TBD. Please cite the published version at https://doi.org/10.1016/j.shpsa.2019.12.006 (C)2020 John P. McCaskey, licensed under CC BY-NC-ND 4.0
} 
based on conceptual rather than propositional units-for us to try capturing them in schematic forms.

For example, a rule of classification logic is that one type of thing cannot be both a subset and a superset of another type. As Socrates insisted to Euthyphro, for example, either piety is a kind of virtue or virtue is a kind of piety - not both. The rule is crucial to building a conceptual framework but not very useful for propositional inference. You could construct a symbolic inference from the rule true for all values of $\mathrm{X}$ and $\mathrm{Y}$-If $\mathrm{X}$ is a species of $\mathrm{Y}, \mathrm{Y}$ is not a species of $\mathrm{X}$; $\mathrm{X}$ is a species of $\mathrm{Y}$; therefore $\mathrm{Y}$ is not a species of $\mathrm{X}$-but the schema just does not do much work. The rule's central role in concept formation does not come from applying an inferential schema. It comes from identifying a potential contradiction that must be avoided.

And non-formal logic is for the most part just a collection of errors not to make. Logic is, after all, just the art of non-contradictory identification. ${ }^{12}$ The conclusion of a first-figure syllogism in Barbara is true because it can be denied only on pain of contradiction. All men are mortal; Socrates is a man; therefore Socrates is mortal. To say Socrates is not mortal would contradict the premise that all men are. The denial would violate the (non-formal) principle of identity and the (non-formal) principle of dictum de omni et nullo (what is true of all instances is true of each). Formal rules of logic, such as those governing first-figure syllogisms, are derived from non-formal rules of how to avoid contradictions.

There is no one theoretically complete set of such rules, as there is, say, for first-figure syllogisms. There is, after all, a limited number of ways to combine three terms. But there is no limit to the number of ways you can mis-organize your thoughts, or ways you can misgeneralize. Aristotle, Cicero, Agricola, Ramus, Bacon, Herschel, and Whewell had their catalogs of contradictions to be avoided when making universal generalizations. Their rules all add up to the same thing-you organize your conceptual framework until you are willing to say an exception to a universal statement would remove an instant from the subject or

\footnotetext{
${ }^{12}$ I take the formulation from Ayn Rand. See Peikoff (1993, p. 118). 
predicate class. We have applied enough rules of classifying materials, enough different ways, over a long enough time, that we are willing to say that if something does not attract iron, it is best not to call it a magnet. That is, all magnets attract iron. We are not willing to make such universal claims about swans and the color of their feathers. So the inferences that all swans are white and all magnets attract iron are qualitatively different, though both are arrived at by induction.

Formal theories of induction seek their defense in the belief that ampliation is grounded in the mind's ability to infer a universal proposition from propositions about particulars. Material theories seek their defense (or should) in the belief that ampliation is grounded in the mind's ability to form universal concepts from observation of individual things. Which class of theories is right depends on where in fact ampliation enters human cognition.

\section{The Call to Revive and Rebuild}

We should welcome John Norton's forceful and effective attacks on formal theories of induction as a call to revive non-formal ones. At one point, Norton speculates how Marie Curie would have explained her inferences about all radium chloride based on such small samples. But we need not speculate. Curie was simply applying the scientific method of classificatory science that dominated chemical physics in her day. Curie was an infant when Mendeleev discovered the periodic system of elements. She began her chemical training under one of his assistants. ${ }^{13}$ Her life's research project-and that of basically all research chemists at the timewas an integration of observations into Mendeleev's framework. We can study her work and the textbooks she read. Practitioners of non-formal induction from Fabricius and Harvey to Lyell and Darwin told us plenty about how they went about their work and why. We do not need to reverse-engineer their methods and force them into our current way of thinking. We

13 The assistant was her cousin, Józef Boguski. Mendeleev himself visited Curie's laboratory in 1902. Mendeleev was greatly troubled by how best to think about radioactivity. See Gordin (2004, p. 213). The scientific community needed to decide whether unstable, radioactive materials were rightly categorized as elements in Mendeleev's periodic table and how best to characterize the particles emitted. Radioactivity challenged what it means for something to be an element. 
can just study the tracts on non-formal, inductive, scientific method that they wrote, read, and cited and understand those tracts as they were intended to be.

But we would also need to bound the concept as they did. They limited induction to the development of universals from particulars. They did not assume that all induction is uncertain and that any uncertain inference is an induction. They did not sweep under that moniker any and all uncertain inferences, from "All mammals are warm-blooded" to "Jackie will love these new donuts." They treated "All magnets attract iron" as the result of an induction, even though there is no risk that it might not be true. They did not treat the inability to draw exceptionless inferences as the defining characteristic of anything.

John Norton is right that trying to treat induction as a formal sort of inference leads to endless trouble and that we should treat it non-formally instead. Fortunately, we can do that without reinventing the wheel. We can return to the days-from Bacon and Galileo to Whewell and Darwin-when induction was fundamentally a classification logic, ampliation was presumed to reside in our conceptual rather than our inferential faculty, and inductive inferences were not simply the ones that risk producing false conclusions from true premises. Norton calls on us to rethink induction in light of the troubles caused by treating it as a sort of formal inference. We may need to rethink parts that even Norton himself has not yet reconsidered.

If we do, we can build on the ground Norton has cleared for us an induction that has none of the skepticism now taken for granted in studies of induction, yet also not as bereft of guiding and universal principles as Norton proposes. We have much to draw upon in earlierand still inadequately appreciated-works on material induction, beginning with Socrates' quest for good definitions and Aristotle's quest for general yet non-formal norms of scientific inquiry. Misunderstanding of one short chapter (B 23) in the Prior Analytics has masked just how much insight, especially in the Topics, Aristotle has to offer on material induction. Bacon and Whewell need to be read as the material inductivists they were, not as naïve and failed

\footnotetext{
Preprint accepted for publication in Studies in History and Philosophy of Science, date TBD. Please cite the published version at https://doi.org/10.1016/j.shpsa.2019.12.006 (C)2020 John P. McCaskey, licensed under CC BY-NC-ND 4.0
} 
formal inductivists. Even historical figures far from the mainstream of induction theory, such as John Buridan and Peter Ramus, warrant study. The methodological writings of eminent scientists steeped in material induction, from Fabricius in the sixteenth century to Faraday and Darwin in the nineteenth, offer untapped insights. John Norton's work highlights how important recent historical and philosophical studies of these figures are to the latest developments in philosophy of induction. ${ }^{14}$ Whether he fully appreciates it or not, Norton's work calls us to revisit and to revive a great tradition of material induction.

Let us begin.

\footnotetext{
${ }^{14}$ For Aristotle, the important work in this direction has been done by James G. Lennox. Lennox (2011) is one recent example, Lennox in press an even more important one. (I take the phrase "non-formal norms of scientific inquiry" from Lennox.) For the misunderstanding of Aristotelian induction, see McCaskey (2007). For Whewell, the important revisionist work is by Laura J. Snyder. See, among others, Snyder (1997, 1999, 2006, 2019). On Baconian induction as a revival of ancient material induction, see McCaskey (2006). Thanks to the recent work of Gyula Klima, we now have ready access to the crucial writings of Buridan. See Buridan (2001). For just one example of non-formal induction at work in the Renaissance, see Cunningham (1985); for an example from the nineteenth, see Steinle (2016).
}

\footnotetext{
Preprint accepted for publication in Studies in History and Philosophy of Science, date TBD. Please cite the published version at https://doi.org/10.1016/j.shpsa.2019.12.006 (C2020 John P. McCaskey, licensed under CC BY-NC-ND 4.0
} 


\section{Acknowledgements}

I thank James G. Lennox and especially Laura J. Snyder, for discus-sions on these topics and for comments on earlier drafts; anonymous referees and the journal's managing editor, Micheál Lacey, for very thoughtful comments; the editors of this special issue, especially for the suggestion that I contribute an historical piece; and, of course, John D. Norton, for his years of work on induction, for many conversations on this and other topics, and for the countless generous courtesies he has extended to me over the years. I also thank Maryanne Kowaleski, Sus-anne Hafner, and Nicholas Paul of the Center for Medieval Studies at Fordham University for providing such a supportive environment in which to work on this essay and a related forthcoming book on the history of induction. 


\section{References}

Bacon, F. (2000). In M. Silverthorne, \& L. Jardine (Eds.), The new Organon. London: Cambridge University Press.

Buridan, J. (2001). In G. Klima (Ed.), Summulae de Dialectica. Yale University Press.

Cunningham, A. (1985). Fabricius and the "Aristotle Project" in anatomical teaching and research at Padua. In Wear, French, and Lonie (Eds.), The medical renaissance of the sixteenth century. Cambridge University Press.

Ducheyne, S. and McCaskey, J. P. (2014). The sources of Mill's view of ratiocination and Induction. In Mill's A System of Logic: Critical appraisals. London: Routledge.

Gordin, M. D. (2004). A well-ordered thing: Dmitrii Mendeleev and the shadow of the periodic table. Basic Books.

Green, T. H. (1885). In R. L. Nettleship (Ed.), 1. Works of Thomas Hill Green. London: Longmans, Green, and Co.

Hume, D. (1874). A treatise on human nature, being an attempt to introduce the experimental method of reasoning into moral subjects. T. H. Green, \& T. H. Grose (Eds). London: Longmans, Green, and Co.

Jevons, W. S. (1874). The Principles of science: A treatise on logic and scientific method. London and New York: Macmillan.

Lennox, J. G. (2011). Aristotle on Norms of Inquiry. HOPOS: The fournal of the International Society for the History of Philosophy of Science, 1, 23-46.

Lennox, J. G. (in press). Aristotle on Norms of Scientific Inquiry. Cambridge University Press.

McCaskey, J. P. (2007). Freeing Aristotelian epagōgē from Prior Analytics II 23. Apeiron: A journal for ancient philosophy and science, 40, 345-74.

Preprint accepted for publication in Studies in History and Philosophy of Science, date TBD. Please cite the published version at https://doi.org/10.1016/i.shpsa.2019.12.006

()2020 John P. McCaskey, licensed under CC BY-NC-ND 4.0 
McCaskey, John P. (2006). Regula Socratis: The Rediscovery of Ancient Induction in Early Modern England. (PhD Dissertation). Stanford University.

Mill, J. S. (1843). A system of logic: Ratiocinative and inductive. London: John W. Parker.

Monck, W. H. S. (1881). Sir William Hamilton. New York: G.P. Putnam’s Sons.

Norton, J. D. (2003). A material theory of induction. Philosophy of Science, 70, 647-70.

Norton, J. D. (2005). A little survey of induction. In P. Achinstein (Ed.). Scientific evidence: Philosophical theories and applications. Baltimore: Johns Hopkins University Press.

Norton, J. D. (2010). There are no universal rules for induction. Philosophy of Science, 77, 76577.

Norton, J. D. (2014). A material dissolution of the problem of induction. Synthese, 191, 671-690.

Norton, J. D. (2019). The Material Theory of Induction. Department of History and Philosophy of Science, University of Pittsburgh. https://www.pitt.edu/ jdnorton/homepage/ cv.html\#material_theory. (Accessed 5 January 2020.)

Peikoff, Leonard (1993). Objectivism: The philosophy of Ayn Rand. New York: Meridian.

Peirce, C. S. (1878). Illustrations of the logic of science. Popular Science Monthly 12.

Rees, G. (2004). Novum Organum and the texts of 1620: Fluctuating fortunes. Oxford Francis Bacon (Vol. XI). Oxford University Press.

Reid, T. (1846). The works of Thomas Reid, D. D. Edinburgh: Maclachlan, Stewart, and Co. Rinne, F. (1903). Verwandtschaft von Bromradium und Brombaryum in krystallographischer Hinsicht. Centralblatt für Mineralogie, Geologie und Palaeontologie, 134-141.

Snyder, L. J. (1997). Discoverers' induction. Philosophy of Science, 64, 580-604.

Snyder, L. J. (1999). Renovating the Novum Organum: Bacon, Whewell and induction,” Studies in the History and Philosophy of Science, 30, 531-557.

Snyder, L. J. (2006). Reforming philosophy: A victorian debate on science and society. Chicago: University of Chicago Press. 
Snyder, Laura J. (2019). William Whewell. In E. N. Zalta (Ed.), Stanford encyclopedia of philosophy. (Spring 2019 ed.). https://plato.stanford.edu/archives/spr2019/entries/ whewell/. (Accessed 5 January 2020).

Steinle, F. (2016). In A. Levine (Trans.) Exploratory experiments: Ampère, Faraday, and the origins of electrodynamics. Pittsburgh: University of Pittsburgh Press. (Translation of Explorative Experimente: Ampère, Faraday und die Ursprünge der Elektrodynamik.

Stuttgart: Franz Steiner, 2005.)

Whately, R. (1826). Elements of Logic. London: Mawman.

Whitney, W. D. (1889). The century dictionary. New York: The Century Co. 